Subscriber access provided by Miami University Libraries

Article

\title{
Proteomics analysis of Formalin Fixed Paraffin Embedded tissues in the investigation of prostate cancer
}

Anna Mantsiou, Manousos Makridakis, Konstantinos Fasoulakis, loannis Katafigiotis, Constantinos

A. Constantinides, Jerome Zoidakis, Maria G. Roubelakis, Antonia Vlahou, and Vasiliki Lygirou

J. Proteome Res., Just Accepted Manuscript • DOI: 10.1021/acs.jproteome.9b00587 • Publication Date (Web): 04 Nov 2019

Downloaded from pubs.acs.org on November 5, 2019

\section{Just Accepted}

"Just Accepted" manuscripts have been peer-reviewed and accepted for publication. They are posted online prior to technical editing, formatting for publication and author proofing. The American Chemical Society provides "Just Accepted" as a service to the research community to expedite the dissemination of scientific material as soon as possible after acceptance. "Just Accepted" manuscripts appear in full in PDF format accompanied by an HTML abstract. "Just Accepted" manuscripts have been fully peer reviewed, but should not be considered the official version of record. They are citable by the Digital Object Identifier (DOI®). "Just Accepted" is an optional service offered to authors. Therefore, the "Just Accepted" Web site may not include all articles that will be published in the journal. After a manuscript is technically edited and formatted, it will be removed from the "Just Accepted" Web site and published as an ASAP article. Note that technical editing may introduce minor changes to the manuscript text and/or graphics which could affect content, and all legal disclaimers and ethical guidelines that apply to the journal pertain. ACS cannot be held responsible for errors or consequences arising from the use of information contained in these "Just Accepted" manuscripts. 


\section{Title: Proteomics analysis of Formalin Fixed Paraffin Embedded tissues in the investigation of 2 prostate cancer}

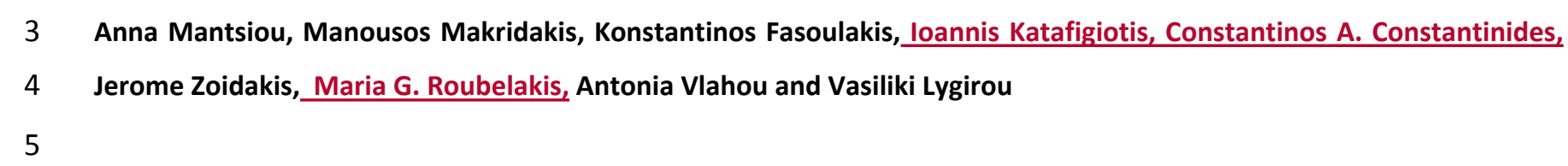

\section{Abstract}

Prostate cancer ( $\mathrm{PCa}$ ) is one of the leading causes of death in men worldwide. The molecular features, associated with the onset and progression of the disease, are under vigorous investigation. Formalin-fixed paraffinembedded (FFPE) tissues are valuable resources for large-scale studies, however, their application in proteomics is limited due to protein cross-linking. In this study, the adjustment of a protocol for the proteomic analysis of FFPE tissues was performed which was followed by a pilot application on FFPE PCa clinical samples to investigate whether the optimized protocol can provide biologically relevant data for the investigation of PCa. For the optimization, FFPE mouse tissues were processed using eight seven protein extraction protocols including combinations of homogenization methods (beads, sonication, boiling) and buffers (SDS based and UreaThiourea based). The proteome extraction efficaiency was then evaluated based on protein identifications and reproducibility using SDS electrophoresis and high resolution LC-MS/MS analysis. Comparison between the FFPE and matched fresh frozen (FF) tissues, using an optimized protocol involving protein extraction with an SDSbased buffer following beads homogenization and boiling, showed a substantial overlap in protein identifications (1106 common between the 1214 identified in FF and 1249 identified in FFPE)-with a strong correlation in relative abundances $\left(r_{s}=0.782 \underline{0.819}, p_{-}<\underline{0.001)}\right.$. Next, FFPE tissues ( 3 sections, $15 \mu \mathrm{m}$ each per sample) from 10 patients with PCa corresponding to tumor (GS=6 or $G S \geq 8$ ) and adjacent benign regions were processed with the optimized protocol. Extracted proteins were analyzed by GeLC-MS/MS followed by statistical and bioinformatics analysis. Proteins significantly deregulated between PCa GS $\geq 8$ and PCa GS=6 represented extracellular matrix organisation, gluconeogenesis and phosphorylation pathways. Proteins deregulated between cancerous tissues-and adjacent benign tissues-counterparts, showed-reflected increased translation, peptide synthesis and protein metabolism in the former, which is consistent to-with the literature. In conclusion, the results support the relevance of the proteomic findings in the context of PCa and the reliability of the optimized protocol for proteomics analysis of FFPE material.

\section{Keywords}

31 FFPE; Protocol adjustment; Prostate cancer; Proteomics; LC-MS/MS 


\section{Introduction}

Prostate cancer (PCa) ranks as the second most frequently diagnosed cancer and the fifth leading cause of cancer-related deaths in men's population worldwide, with 1.3 million new cases and 359,000 deaths in 2018 [1]. The major clinical challenge is the inability of current biomarker tests and stratification systems to reliably predict the disease outcome and distinguish the indolent from the highly aggressive PCa tumors [2]. ProstateSpecific Antigen (PSA) is currently the most widely used biomarker test for PCa diagnosis and prognosis. However, it has poor specificity [3] and consequently may lead to unnecessary biopsies and high rates of overdiagnosis and overtreatment. In the last decade, various molecular tests based on genetic markers have been FDA approved by FDA for PCa diagnosis (SelectMDX, Progensa) and prognosis (OncotypeDx, Prolaris, Decipher), however the lack of cost effectiveness combined with the suboptimal accuracy rates hinder their wide use [4]. Taking these into consideration, there is an emerging clinical need for PCa molecular biomarkers of high specificity and sensitivity that will assess more accurately the disease progression.

Even though main advancements in the characterization of PCa tissue at the DNA/RNA levels have been made, reflected in the current molecular subtyping schemes of the disease [5], large-scale proteomics studies with validated results remain scarce [6].information at the proteome level is still largely lacking. In addition, The vast majority of the reported proteomics studies on PCa use have applied relatively low resolution proteomic technologies (2DE, 2D-DIGE, RPPA) which are semi-quantitative and provide inadequate proteomic coverage [6-8]. Nevertheless, the number of high resolution proteomics studies on PCa has risen in the last five years uncovering new insights on PCa progression $[6,9,10]$.

Formalin-Fixed Paraffin-Embedded (FFPE) tissue blocks represent a valuable source of samples for clinical and translational research, as pathology departments routinely archive them in vast numbers. Tissue fixation routinely takes place in formalin solution (for $24-48 \mathrm{~h}$ ) enabling the storage of samples in ambient condition for decades [11]. Extracting the molecular profile of FFPE tissues enables prospective and retrospective studies to be performed with adequate statistical power and could greatly facilitate biomarker discovery and validation. In addition, proteomic assessment of FFPE tissue samples can provide precious insights into the molecular mechanisms underlying the disease pathology and hence facilitating the discovery of novel drug targets [6]. Molecular assays for oncological prognosis have been already developed using FFPE tissue samples. Oncotype DX prostate cancer assay, which is a 17-gene RT-PCR assay predicting the aggressiveness of prostate cancer, is such an example [12]. 
The protein profiling of FFPE tissues is challenging due to the formalin-induced chemical modifications of proteins $[13,14]$. The induced cross-linking decreases the protein solubility and inhibits its digestion by preventing trypsin or other endopeptidases to reach their cleaving sites $[15,16]$. In addition, amino acid chemical changes are frequently induced $[11,16,17]$. As a result, the proteomics output may be compromised. Since the first reported effort to optimize protein extraction from FFPE, in 1998, to optimize protein extraction from FFPE, using $2 \%$ SDS combined with sequential heating steps at $100{ }^{\circ} \mathrm{C}$ and $60^{\circ} \mathrm{C}$ [18], it was not until 2005 that a shotgun-based workflow for the analysis of FFPE tissue was proposed by Hood et al. [19], using human PCa clinical samples. In this case, protein extraction relied on the use of a commercial kit and heating at $95^{\circ} \mathrm{C}$ for 90 min. Upon analyzing the samples by label-based nano-RP-LC-MS/MS- about 1,000 proteins (702 proteins from benign prostatic hyperplasia and 1,153 proteins from prostate carcinoma with 69 proteins being differentially expressed between the two) were reported [19]. Since then, the studies that investigated the global proteome proteomic changes in PCa FFPE samples are scarce ${ }_{2}$ using in some cases low resolution proteomics techniques (2D Gel, MALDI TOF) or extensive fractionation and/or expensive labeling protocols [20-23].

Here we describe a simple and efficient protocol for proteomics analysis of FFPE tissue and demonstrate its efficacy in providing biologically relevant information in the context of PCa through a pilot study, involving the analysis of low versus high risk prostate cancerpCa.

\section{Materials and Methods}

\subsection{Tissue samples}

ArchivalFFPE mouse tissue samples, as per availability, [tkidney and liver; fixed in $10 \% \mathrm{v} / \mathrm{v}$ formalin in water overnight, dehydrated in $70 \%$ ethanol, embedded in paraffin and stored at room temperature (RT)] were employed for protocol optimization. In some cases, respective frozen tissue samples were also available.

Archival FFPE prostate tissue specimens from 10 patients operated-who had undergone surgery at the Ippokrateio Hospital, Athens, were used in the study, in line to ethics requirements (the study was approved from the Ethics Committee of the Medical School, National and Kapodistrian University of Athens, with protocol number 45/2018). The clinico-pathological information associated to-with these specimens is provided in Table S1. FFPE sections $\left(4 \_\mu \mathrm{m}\right)$ from each block were stained with hematoxylin/eosin and examined by the Pathologist pathologist to localize the site of the tumor and evaluate the Gleason grading. Then, tumor and benign regions

91 were collected by microdissection excised from the adjacent unstained sections. The samples used in the current 
counterparts-adjacent tissues ( $n=5$; referred to as $1 b-5 b)$; GS $\geq 8$ cancerous tissue ( $n=5$; referred to $6 a-10 a)$ and their benign adjacent tissues counterparts $(n=4$; referred to as $6 b-9 b)$.

\subsection{Protein extraction from FFPE and FF tissue with the optimized protocol}

For each FFPE sample, 3 - 4 sections 15 - $20 \mu \mathrm{m}$ each were obtained and combined in a 2 ml eppendorf tube

for further processing. This included, deparaffinization through three incubations in xylene (first two for 5 min each and the last for $1 \mathrm{~min}$ ), each one followed by centrifugation for $3 \mathrm{~min}$ at 13,000 rpm, at RTroom temperature (RT). The sections were then rehydrated through a series of ethanol and distilled water washes (100\% ethanol for $2 \mathrm{~min}, 95 \%$ ethanol for $1 \mathrm{~min}, 70 \%$ ethanol for $1 \mathrm{~min}$, distilled water for $1 \mathrm{~min}$ ), each one followed by centrifugation for 3 _min at $13,000 \mathrm{rpm}$, at RT. Upon rehydration, the tissue pellets were left to airdry for 30 min at RT. The subsequent steps were common for both FFPE and fresh frozen (FF) samples (without any prior steps for the latter). The samples were resuspended in $200 \mu \mathrm{l}$ of FASP buffer (pH 8), containing 100 $\mathrm{mM}$ Tris- $\mathrm{HCl}, 4$ \% SDS, $100 \mathrm{mM}$ DTE. For homogenization, 0.9 - $2.0 \mathrm{~mm}$ stainless steel beads were added to the samples and placed at the bullet blender homogenizer (Bullet Blender Storm BBY24M, Next Advance, USA) in 2 sequential steps: 5 min in at speed 12 and $3 \mathrm{~min}$ in at speed 10 . The homogenates were sonicated for 3 cycles of 5 secends each using a tip sonicator ( $36 \%$ power used), followed by $1 \mathrm{~h}$ of heating at $90^{\circ} \mathrm{C}$ on a heating block. Then, the extracts were centrifuged for $10 \mathrm{~min}$ at $13,000 \mathrm{rpm}$ at RT and the supernatants ( $170 \mu \mathrm{l})$ were transferred in to new $1.5 \mathrm{ml}$ eppendorf tubes and protease inhibitors were added to a final concentration of $3.6 \%$ and stored at $-80 \_\theta_{-}^{\circ} \mathrm{C}$ until use.

The extraction buffers that were tested during the optimization process include: PEB buffer (20 mM TrisHCl, 200 mM DTE, 2\% SDS, 20\% Glycerol); Urea-Thiourea buffer (7 M Urea, 2 M Thiourea, 4\% Chaps, 65 mM DTE, 2\% IPG); and FASP buffer (100 mM Tris-HCl, 4 \% SDS, 100 mM DTE) (Table 1).

Table 1. Seven combinations of homogenization methods and extraction buffers were used for the FFPE extraction optimization

\begin{tabular}{|c|c|c|c|}
\hline $\begin{array}{l}\text { Homogenization means } \\
\text { Extraction buffers }\end{array}$ & bullet blender & $\begin{array}{l}\text { bullet blender, } \\
\text { sonication }\end{array}$ & $\begin{array}{l}\text { bullet blender, } \\
\text { sonication, heating }\end{array}$ \\
\hline $\begin{array}{c}\text { PEB (20mM Tris-HCl, 200mM DTE, } 2 \% \text { SDS, } \\
20 \% \text { Glycerol) }\end{array}$ & $\checkmark$ & & \\
\hline $\begin{array}{c}\text { Urea (7M Urea, 2M Thiourea, 4\% Chaps, } \\
65 \mathrm{mM} \text { DTE, 2\% IPG) }\end{array}$ & $\checkmark$ & $\checkmark$ & $\mathscr{L}$ \\
\hline $\begin{array}{c}\text { FASP (100mM Tris-HCl pH 7.6, SDS 4\%, } \\
\text { 100mM DTE) }\end{array}$ & $\checkmark$ & $\checkmark$ & $\checkmark$ \\
\hline
\end{tabular}


FASP without SDS*

118 119

120

121

122

123

124

125

126

127

128

129

130

131

132

133

134

135

136

137

138

139

140

141

142

143

144

145

146

147

148

\subsection{Protein digestion of FFPE prostate clinical tissues}

The GeLC-MS method [24] was applied. Samples (protein extract from 3 - 4 sections 15 - $20 \mu \mathrm{m}$ each, per sample) were concentrated 10 times (using Amicon Ultra Centrifugal Filters, 3 kDa AWCOMW cut-off) with buffer exchange in $50 \mathrm{mM}$ ammonium bicarbonate, $\mathrm{pH}$ 8.5. The total amount of the concentrated sample (18 $20 \mu$ l) was then loaded on the polyacrylamide gel and the rest of the protocol was followed exactly as described in [24]. Trypsinization was performed by adding $600 \mathrm{ng}$ of trypsin, for $12-16 \mathrm{~h}$, at RT in the dark, in a humidified container. Peptide extraction followed and the peptide solution was lyophilized [24].

\subsection{LC-MS/MS analysis and MS data processing}

LC-MS/MS analyses were performed on a Dionex Ultimate 3000 UHPLC nano flow system coupled to a Thermo Q Exactive mass spectrometer and an Orbitrap Elite. Prior to the analysis, each sample was reconstituted in $12 \mu \mathrm{l}$ mobile phase $\mathrm{A}(0.1 \%$ Formic $\mathrm{Acid}, \mathrm{pH} 3.5)$ and $6 \mu$ l loaded on the column. In all cases, raw files were processed with Thermo Proteome Discoverer 1.4 software, utilizing the Sequest search engine and the UniProt human (downloaded on 16/12/2018 including 20243 reviewed entries) and mouse (downloaded on 22/11/2017 including 16935 reviewed entries) fasta canonical data-bases (downloaded on 16/12/2018 including 20243 reviewed entries). The search was performed using carbamidomethylation of cysteine as static and oxidation of methionine as dynamic modifications. Two missed cleavage sites, a precursor mass tolerance of 10 ppm and fragment mass tolerance of 0.05 Da were allowed. For both the human and the mouse samples, the filters used were as follows: Peptide: High Confidence (FDR q value based $=0.01$ ) and Medium Confidence (FDR q value based $=0.05)$, peptide rank: Maximum rank=1, peptide grouping: enabled, protein grouping: enabled.

\subsection{Statistical analysis}

The peak area of precursor ions was used to assess the relative abundance of the identified proteins (label -free method). Protein abundance in each sample was calculated as the sum of all peptide peak areas from the extracted chromatogram, normalized as follows (ppm): Protein peak area/Total peak area per sample $\times 10^{6}$. For the comparison between the cancerous tissues (GS6 and GS $\geq 8 ; n=9$ ) and the adjacent benign tissues (GS6 and $\mathrm{GS} \geq 8 ; n=9$ ), a threshold of $30 \%$ was applied (total number of samples $n=18$ ). For the rest of the comparisons, due to the smaller sample size ( $n=4$ or 5 per group) proteins detected in at least $60 \%$ of samples in at least one group were considered for quantification and statistical analysis to increase reliability of results. The non- 
parametric Mann-Whitney U- test (two tailed, unadjusted) was utilized for defining statistical significance. The test was applied on each of the comparisons using SPSS software (IBM SPSS Statistics for Windows, Version 22.0. Armonk, NY: IBM Corp. Released 2013). Fold change for each comparison were-was calculated as follows: mean value of the case group / mean value of the control group. Proteins with a fold change of $\geq 1.5$ (up-regulated) or $\leq 0.67$ (down-regulated) were considered as differentially expressed, whereas proteins that are significantly differentially expressed are those that fulfilled both the 1.5-ratio cutoffs and also have a p-value $\leq 0.05$ from the Mann-Whitney test.

\subsection{Pathway-Bioinformatics analysis}

Pathway analysis was performed using the ClueGO plug-in in Cytoscape 3.5.1. Only the significantly deregulated proteins were used as input and they were assigned into two separate lists according to their regulation (up- or down- regulated in cases versus controls). Ontologies were retrieved from the REACTOME pathway database (organism: Homo Sapiens, 2,240 terms with 10,664 available unique genes, updated on March 18, 2019) and only statistically significant pathways (Benjamini-Hochberg corrected p-value $\leq 0.05$, twosided hypergeometric test) were taken into account. The rest of the settings were used as default. For simplification, the leading term from each group is presented. The percentage of detected features over all associated genes per group is also displayed under the column "\% association" (Tables S2a-S2e).

For the disease association analysis the Open Targets platform was used. The hypergeometric distribution and a scoring process based on evidence from 20 data sources (e.g. Uniprot, GWAS Catalog and PheWAS) was used to allow prioritization of targets based on the strength of their association with a disease. The scoring process generate a relevance $p$ value representing the probability that the given list of targets are specific to a disease. Only urological cancers with a relevance $p$-value $\leq 0.05$ were selected.

\section{Results}

\subsection{Establishment of optimized protocol}

Initial experiments were performed to establish an efficient and simple protocol for protein extraction from FFPE tissue. The tested methods were based on earlier studies [20-23] and experience in our laboratory from the analysis of tissue material of limited amount $[25,26]$, taking also into account compatibility with mass spectrometry. The methods specifically included the use of four different protein extraction buffers in combination to different homogenization means (Table 1 and Figures S1a-S1b). In all cases, 3 sections of archival liver and kidney FFPE tissues (as per availability) were employed, to simulate realistic scenarios of elinical available starting material scenariosfrom clinical samples. The yield and quality of extracted proteins were 
181 initially evaluated by SDS-PAGE analysis (Figure S1a). Based on this, following which, application of Tris-HCl, SDS 182 and DTE (FASP buffer) in combination with bead homogenization, sonication and boiling, was selected for 183 further detailed evaluation by GeLC-MS analysis. An overview of the applied workflow for the optimization of 184 the protein extraction from FFPE tissues is illustrated in Figure_1.

\begin{tabular}{|c|c|c|c|c|}
\hline $\begin{array}{c}\text { Sectioning of the } \\
\text { FFPE tissue block }\end{array}$ & $\begin{array}{c}\text { Deparaffinization } \\
\text { and rehydration }\end{array}$ & $\begin{array}{c}\text { Tissue digestion and } \\
\text { protein extraction }\end{array}$ & $\begin{array}{c}\text { Quality } \\
\text { assessment }\end{array}$ \\
\hline FFPE tissue bock & Quantity \\
assessment
\end{tabular}

\begin{tabular}{|c|c|c|c|c|}
\hline $\begin{array}{c}\text { Sectioning of the } \\
\text { FFPE tissue block }\end{array}$ & $\begin{array}{c}\text { Deparaffinization } \\
\text { and rehydration }\end{array}$ & $\begin{array}{c}\text { Tissue digestion and } \\
\text { protein extraction }\end{array}$ & $\begin{array}{c}\text { Quality } \\
\text { assessment }\end{array}$ \\
\hline TFPE tissue bock & Quantity \\
assessment
\end{tabular}

Figure 1. Overview of the applied workflow for the FFPE protein extraction optimization. Eight Seven protocols were tested and evaluated for the protein extraction efficiency-efficacy from FFPE tissues.

For further evaluation of the efficaiency of the protocol, a side by side comparison of FFPE tissue with respective fresh frozen (FF) mouse kidney tissue material was also performed. Specifically, 4 FFPE replicates and $2 \mathrm{FF}$ replicates using different sections of the same sample for each type were used. In our analysis, we used reasonably stringent criteria (detailed in materials-Materials and methodsMethods) in order to eliminate most of the false positive protein identifications (IDs). bBased on these criteria, which 14802,056 unique proteins derived from a list of 10661 identified peptides-were in total detected. The full list of proteins is reported in 
200 Table S3a. Among the proteins that were identified, 853 identifications were based on $\geq 2$ peptides and 627 were 201 single peptide identifications. The selected protocol yielded a similar number of protein identifications-IDs from 202 both FF and FFPE tissue (FF IDs: 1,736 1214 in 2 samples, FFPE IDs: 1,4371249 in 4 samples) (Table S3a) and it 203 was also found to-provided reproducible results both within and between the two different preservation 204 methodssample types: an overlap rate of about $63-7251-62 \%$ among the total IDs pf-of the FFPE samples 205 ( $n=4$ replicates) and a $93-9680-86 \%$ among the total IDs in FF samples ( $n=2$ replicates) were noted. In addition, 206 for the common proteins identified in all samples of a group (FF: 1,216, FFPE: 530), a high overlap between the 207 FF and FFPE samples was noted with 610-502 proteins detected in both types of samples (Figure 2A and Table 208 S3b). Importantly, a strong positive correlation in the relative abundances of the common proteins detected in 209 all-the FFPE and FF samples was noted (Spearman's rank-order correlation was also-positive and statistically 210 significant $\left(r_{s}=0.8460 .819, p<0.01,2\right.$-tailed) (Figure 2B and Table S3b). Proteins identified from FF and FFPE 211 samples were also mapped using the Gene Ontology term mapper (https://go.princeton.edu/cgi212 bin/GOTermMapper) for cellular compartments. The generic terms Cytoplasm, Membrane and Nucleus were 213 used for simplification. As shown in Figure 3, the detected proteins are distributed between the three main 214 cellular compartments in a very similar way for the FFPE and FF samples (Figure 3). The same applies when 215 protein segregation by molecular function was investigated as shown in Figure S2.

A

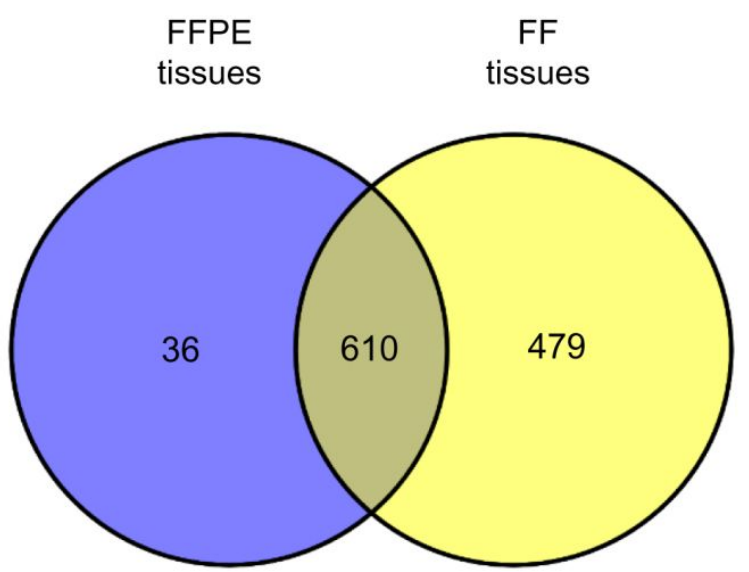

B

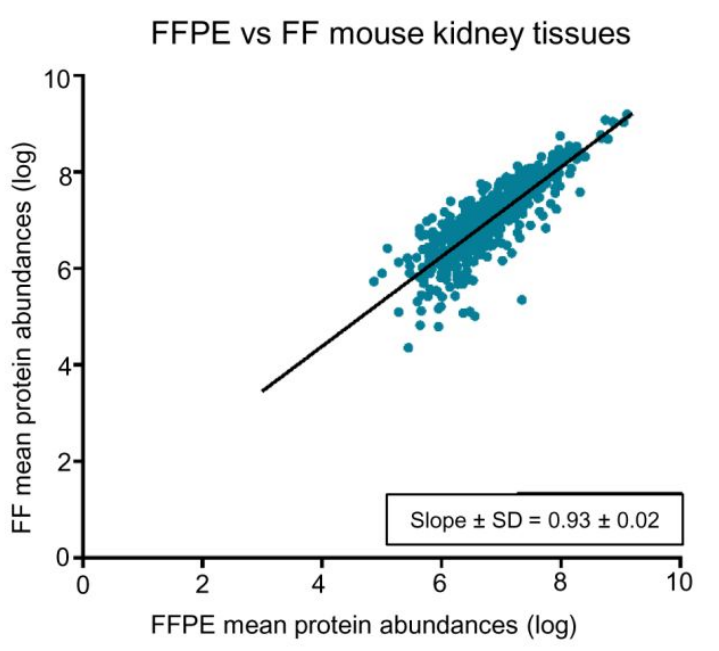


A

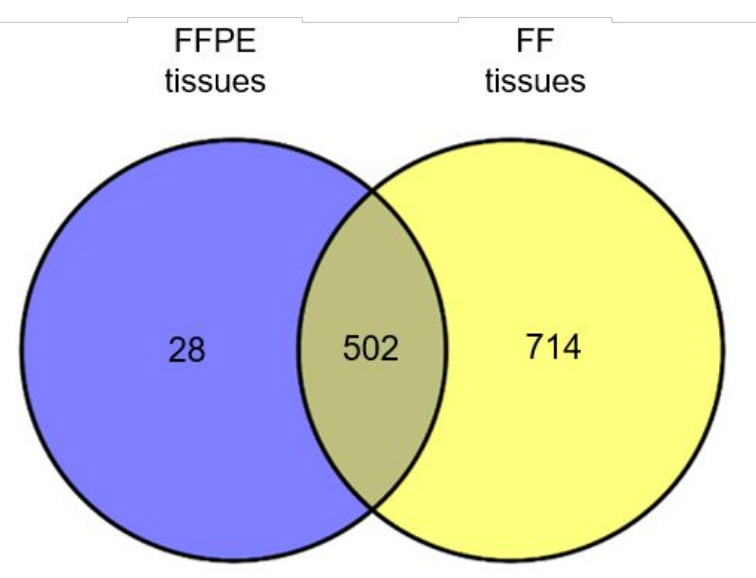

B

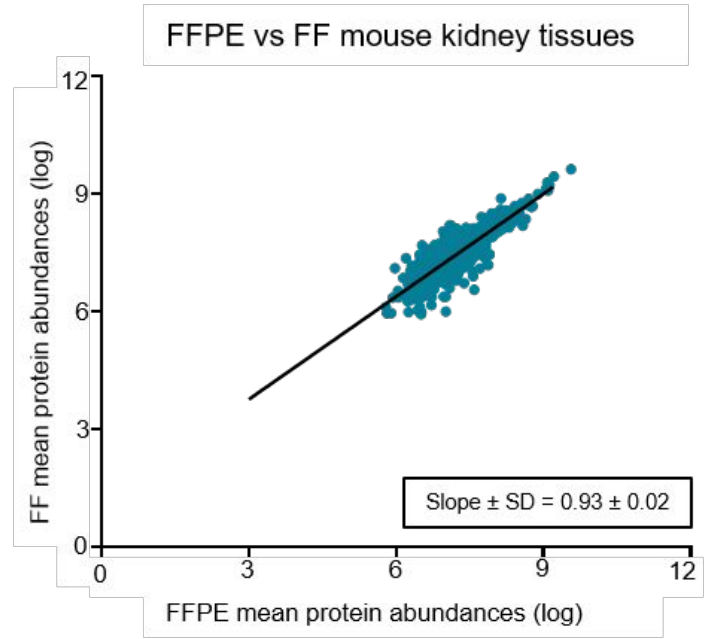

217

218

219

220

221

222

223

224

Figure 2. Reproducibility and effectiveness of the optimized proteomics protocol shown in a side by side comparison of FFPE with respective FF tissues. A. The Venn diagram shows that there is significant overlap ( $n=610$-502 common identifications) among the proteins identified in all samples per group ( $n=4$ for FFPE; $n=2$ for FF) FFPE and FF samples. B. A strong positive correlation is noted between the relative abundances of the 610 $\underline{502}$ common proteins identified in all FF and FFPE samples (Spearman's rho $=0.846 \underline{0.819}$ ).
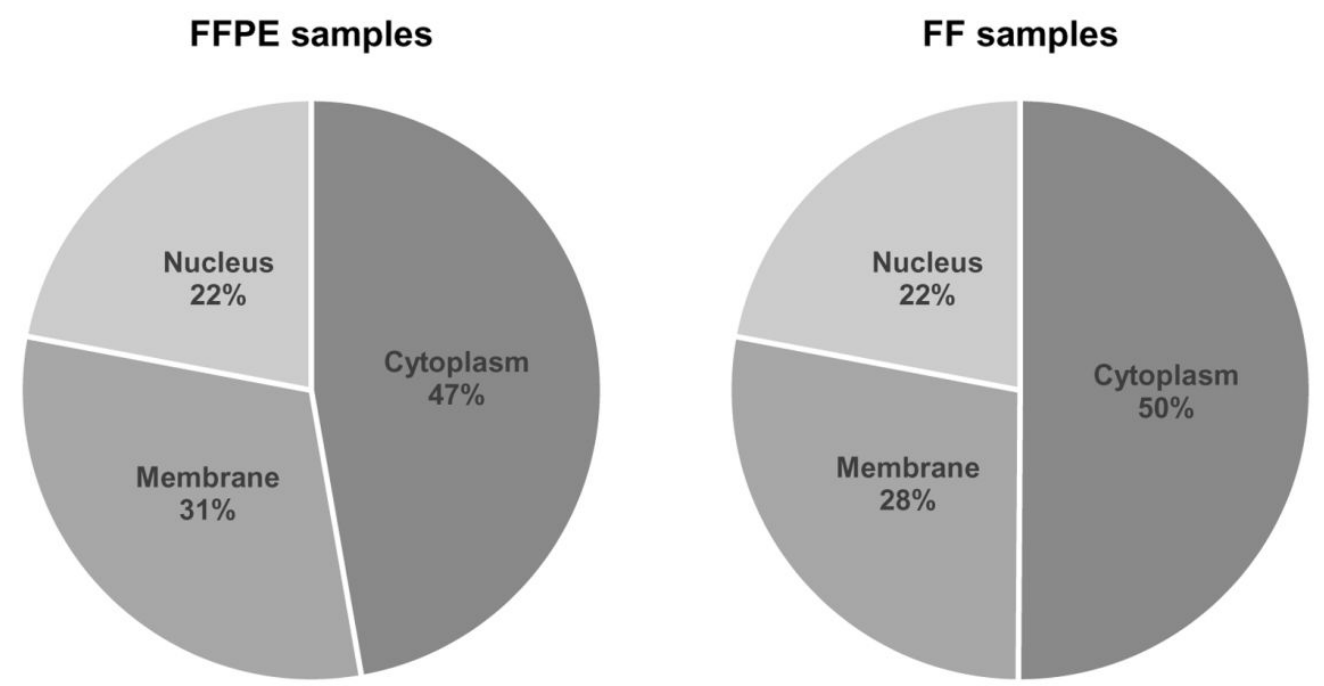

Figure 3. Distribution of the total number of proteins identified in FF and FFPE tissues among the three main cellular compartments. The percentages have been calculated against the total component hits.

\subsection{Application in analysis of FFPE PCa tissue}


231 The optimized protocol was then implemented in a preliminary study aiming to analyze archived clinical 232 prostate FFPE samples representing different risk categories. Specifically, Tthe study specifically involved the 233 analysis of 18 FFPE PCa tissue samples, representing GS=6, GS $\geq 8$ and respective adjacent benign regions. 234 Analysis by GeLC-MS/MS, in this case, provided a mean of approximately 700 proteins per sample, apparently $\underline{\text { a }}$ 235 lower number compared to the-obtained protein identifications obtained during the protocoloptimization-in 236 mouse FFPE tissues $\overline{:-\bar{\prime}}$ This result is likely attributed to differences in fixation and storage conditions (tists-the 237 lists of detected proteins is are provided in Table S4a).

238 Five different comparisons were performed: $\mathrm{GS} \geq 8$ cancer versus $\mathrm{GS}=6$ cancer tissue, $\mathrm{GS} \geq 8$ adjacent benign 239 versus $\mathrm{GS}=6$ adjacent benign tissue, $\mathrm{GS}=6$ cancer versus $\mathrm{GS}=6$ adjacent benign tissue, $\mathrm{GS} \geq 8$ cancer versus $\mathrm{GS} \geq 8$ 240 adjacent benign tissue, and all analyzed cancer samples (GS=6 and GS $\geq 8$ )-cancer tissues versus all analyzed 241 benign samples (GS=6 and $G S \geq 8$ adjacent benign tissues). To graphically represent the proteomic changes 242 between the different groups of tissuessamples, a volcano plot [-log10(P value) vs. $\log 2$ (Fold-change)] was 243 constructed for each one of the comparisons groups_(Figure 4) and the number of differentially expressed 244 proteins per comparison is summarized in Table S4g. As it is-shown in all plots, the population of the proteins 245 above and below the cut-offs is symmetrically distributed. Indicative differentially expressed proteins-changes 246 are shown in tables-Tables 2 and 3 , and includeing proteins involved in of the-ECM organization, chromosomal 247 and cytoskeletal proteins, proteins that-implicated in translation and in the processes of endocytosis-and 248 Lexocytosis. These observations which are-also consistent with already published data as shown in Tables (Table 2492 ; and-Table 3). 

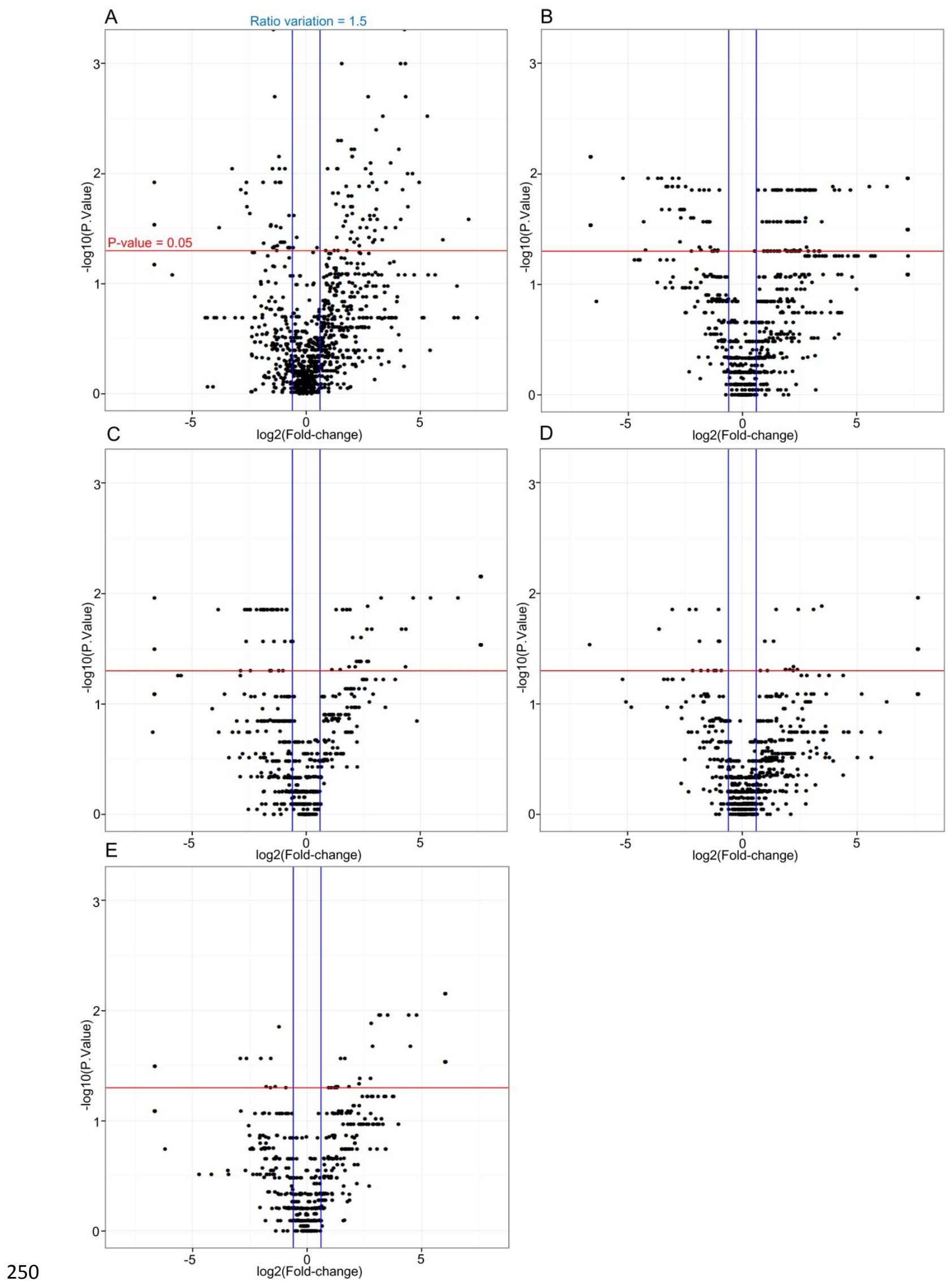
Figure 4. Volcano plot illustrates significantly differentially abundant proteins in the comparisons. A. All cancers ( $G S=6, G S \geq 8$ )-cancer vs. all benign ( $G S=6, G S \geq 8$ adjacent benign), B. GS $\geq 8$ cancer vs. GS=6 cancer, $C$. $\mathrm{GS}=6$ cancer vs. $\mathrm{GS}=6$ benign, $\mathrm{D} . \mathrm{GS} \geq 8$ cancer vs. $\mathrm{GS} \geq 8$ benign and $\mathrm{E} . \mathrm{GS} \geq 8$ benign vs. $\mathrm{GS}=6$ benign. The $-\log 10$ (Benjamini-Hochberg corrected $p$-p-value) is plotted against the log2 (fold change). The non-axial vertical lines denote \pm 1.5 -fold change $\bar{\sim}_{L}$ Points-points to the left of the left-most non-axial vertical line denote protein fold changes less than -1.5 , while points to the right of the right-most non-axial vertical line denote protein fold changes greater than 1.5. The non-axial horizontal line denotes $P$ - -value $=-0.05$ (Mann-Whitney), which is our significance threshold prior to logarithmic transformation; $P$ and points above the non-axial horizontal line represent proteins with significantly differences-differentin abundances (Mann-Whitney $p<-0.05$ ).

Table 2. Top 20 differentially expressed proteins showing the most significant abundance changes-between $\mathrm{GS}=6$ cancer and $\mathrm{GS}=6$ adjacent benign-counterparts, based on a ranking combining the protein abundance ratio and the $p$-value from the Mann-Whitney test ( $\log 2($ Ratio $) *-\log 10(p$-value)). Literature information for proteins that have been previously studied reported in association to PCa are-is also given.

\begin{tabular}{llcccc}
\hline $\begin{array}{c}\text { Accession } \\
\text { ID }\end{array}$ & \multicolumn{1}{c}{ Description } & $\begin{array}{c}\text { Gene } \\
\text { Symbol }\end{array}$ & $\begin{array}{c}\text { Ratio GS6 } \\
\text { cancer Vs GS6 } \\
\text { benign }\end{array}$ & $\begin{array}{c}\text { M-W p- } \\
\text { value GS6 } \\
\text { cancer Vs } \\
\text { GS6 benign }\end{array}$ & Reference* \\
\hline Up-regulated in cancer & & & & \\
\hline P16104 & Histone H2AX & H2AFX & 100.049 & 0.011 & \\
P63241 & Eukaryotic translation initiation factor 5A-1 & EIF5A & 43.448 & 0.011 & [27,28] \\
P13647 & Keratin, type II cytoskeletal 5 $*$ & KRT5 & 25.641 & 0.011 & [29,30] \\
P02511 & Alpha-crystallin B chain * & CRYAB & 20.504 & 0.021 & 0.046 \\
P61158 & Actin-related protein 3 & ACTR3 & 20.334 & 0.021 & \\
P54819 & Adenylate kinase 2, mitochondrial & AK2 & 18.090 & 0.011 & \\
O00148 & ATP-dependent RNA helicase DDX39A & DDX39A & 9.721 & 0.021 & \\
P14550 & Alcohol dehydrogenase [NADP(+)] & AKR1A1 & 7.290 & 0.013 \\
Q96E39 & RNA binding motif protein, X-linked-like-1 & RBMXL1 & 6.436 & 0.021 \\
P32969 & 60S ribosomal protein L9 & RPL9 & 6.330 & \\
\hline
\end{tabular}

Up-regulated in benign

\begin{tabular}{llcccc}
\hline Q15149 & Plectin $*$ & PLEC & 0.266 & 0.014 & [31] \\
P01008 & Antithrombin-III & SERPINC1 & 0.251 & 0.014 & [32] \\
P61019 & Ras-related protein Rab-2A & RAB2A & 0.222 & 0.014 & \\
P08133 & Annexin A6 & ANXA6 & 0.183 & 0.014 & \\
P84243 & Histone H3.3 & H3F3A & 0.180 & 0.014 & \\
P15090 & Fatty acid-binding protein, adipocyte $*$ & FABP4 & 0.166 & 0.014 & [33,34] \\
Q9Y6C2 & EMILIN-1 & EMILIN1 & 0.162 & 0.027 & \\
P18206 & Vinculin & VCL & 0.155 & 0.014 & {$[35,36]$}
\end{tabular}


P98160 Heparan sulfate proteoglycan core protein $\underline{1 *}$

P59665 Neutrophil defensin 1
HSPG2

DEFA1
0.136

0.05

0.014

0.069

\footnotetext{
${ }^{1}$ The asterisk indicates an opposite expression trend compare to the finding in the current study or contradictory literature data ${ }^{2 *}$ L Literature information have has been retrieved from studies comparing PCa versus BPH and/or benign and/or normal in tissues or models by applying different methodological approaches (IHC, Western blot, mass spectrometry).
}

Table 3. Top 20 differentially expressed proteins showing the most significant abundance changes-between $\mathrm{GS} \geq 8$ cancer and $\mathrm{GS} \geq 8$ adjacent benign-counterparts, based on a ranking combining the protein abundance ratio and the $p$-value from the Mann-Whitney test $(\log 2($ Ratio $) *-\log 10(p$-value)). Literature information for proteins that have been previously reported in association to PCa studied are-is also given.

\begin{tabular}{|c|c|c|c|c|c|}
\hline $\begin{array}{l}\text { Accession } \\
\text { ID }\end{array}$ & Description & $\begin{array}{c}\text { Gene } \\
\text { Symbol }\end{array}$ & $\begin{array}{c}\text { Ratio GS } \geq 8 \\
\text { cancer Vs } \\
G S \geq 8 \text { benign }\end{array}$ & $\begin{array}{c}\text { M-W p-value } \\
\text { GS } \geq 8 \text { cancer } \\
\text { Vs GS } \geq 8\end{array}$ & Reference * \\
\hline
\end{tabular}

Up-regulated in cancer

\begin{tabular}{llcccc}
\hline Q13162 & Peroxiredoxin-4 & PRDX4 & 11.000 & 0.013 & {$[6,40,41]$} \\
P08779 & Keratin, type I cytoskeletal 16 & KRT16 & 8.578 & 0.014 & {$[42]$} \\
P02533 & Keratin, type I cytoskeletal 14 ${ }^{*}$ & KRT14 & 5.395 & 0.014 & {$[43]$} \\
P21397 & Amine oxidase [flavin-containing] A & MAOA & 5.273 & 0.049 & {$[44]$} \\
P05141 & ADP/ATP translocase 2 & SLC25A5 & 4.672 & 0.046 & \\
P54819 & Adenylate kinase 2, mitochondrial & AK2 & 4.637 & 0.05 & \\
P31040 & Succinate dehydrogenase flavoprotein & SDHA & 4.204 & 0.049 & {$[45]$} \\
Q9NVD7 & Alpha-parvin & PARVA & 3.708 & 0.049 & {$[46]$} \\
Q9UHG3 & Prenylcysteine oxidase 1 & PCYOX1 & 3.662 & 0.049 & \\
P13639 & Elongation factor 2 & EEF2 & 2.774 & 0.014 & {$[47]$} \\
\hline
\end{tabular}

Up-regulated in benign

\begin{tabular}{|c|c|c|c|c|c|}
\hline 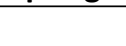 & von Willebrand factor A domain-protein & & & & \\
\hline Q6PCB0 & 1 & VWA1 & 0.489 & 0.014 & \\
\hline P60660 & Myosin light polypeptide 6 & MYL6 & 0.488 & 0.027 & \\
\hline P15088 & Mast cell carboxypeptidase A & CPA3 & 0.355 & 0.05 & \\
\hline P00387 & $\mathrm{NADH}$-cytochrome b5 reductase 3 & CYB5R3 & 0.287 & 0.05 & \\
\hline Q08257 & Quinone oxidoreductase & CRYZ & 0.275 & 0.027 & {$[48,49]$} \\
\hline 075368 & $\begin{array}{l}\text { SH3 domain-binding glutamic acid-rich- } \\
\text { like }\end{array}$ & SH3BGRL & 0.246 & 0.014 & \\
\hline 014558 & Heat shock protein beta- 6 & HSPB6 & 0.223 & 0.05 & \\
\hline Q08380 & Galectin-3-binding protein $*$ & LGALS3BP & 0.203 & 0.014 & [50] \\
\hline P08648 & Integrin alpha- $5 *$ & ITGA5 & 0.121 & 0.014 & [51] \\
\hline
\end{tabular}


$\begin{array}{llll}\text { P30046 D-dopachrome decarboxylase } & \text { DDT } & 0.081 & 0.021\end{array}$

$280{ }^{1}$ The asterisk indicates an opposite expression trend compare to the finding in the current study or contradictory literature data

$281 \quad z^{*}$ Literature information have-has been retrieved from studies comparing PCa versus BPH and/or benign and/or normal in tissues or 282 models by applying different methodological approaches (IHC, Western blot, mass spectrometry).

Significantly differentially expressed proteins were subjected to pathway classification, using the Reactome database, to investigate the deregulated molecular pathways (Figure 5 and Tables S2a-S2e). To simplify the analysis output, only the leading terms of each pathway are presented. Proteins significantly deregulated between the more aggressive $\mathrm{PCa} G \mathrm{~S} \geq 8$ and $\mathrm{PCa}$ of $\mathrm{GS}=6$ were segregated into pathways involved in metabolism and kinase signalling extracellular matrix interactions and organisation, protein phosphorylation and gluconeogenesis, in line to existing literature $[52,53]$ on aggressive forms of prostate cancer (Figure $5 A$ ). On the other hand, when comparing the cancerous tissues with the adjacent benign counterpartstissues, in all cases, the pathways that were enriched in the former, represented translation, peptide synthesis and protein 1 metabolism (Figure 5B, C, D), as expected_[54,55]. 
B

GS6 cancer vs. GS6 benign

Eukaryotic Translation Elongation

The citric acid (TCA) cycle and respiratory electron transport Respiratory electron transport, ATP synthesis disease production by uncoupling proteins
potic Post-translational protein phosphorylation ECM proteoglycans

Diseases of carbohydrate metabolism Branched-chain amino acid catabolism Synthesis of substrates in N-glycan biosythesis Gene and protein expression by JAK-STAT signaling after Interleukin-12 stimulation Platelet Aggregation (Plug Formation) mRNA Splicing - Minor Pathway

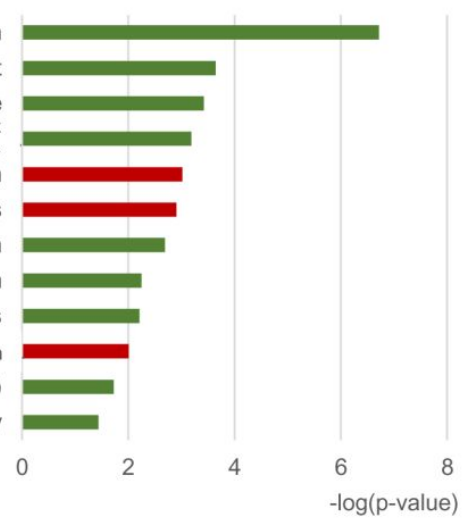

C GS>8 cancer vs. $G S>8$ benign

Eukaryotic Translation Elongation

Peptide chain elongation
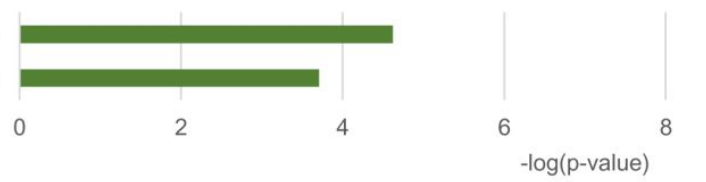

D

GS6 and GS>8 cancer vs. GS6 and GS>8 benign
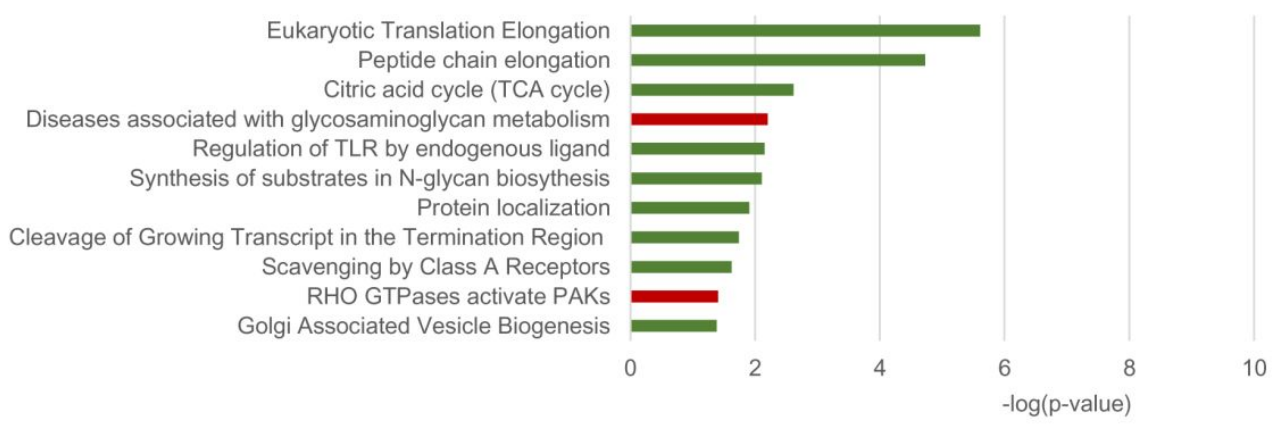
295

Figure 5. Enrichment pathway analysis of the proteins with significant differences between the different comparing groups. Only the leading terms of each pathway group are presented ${ }_{L}$ based on significance which is illustrated from the size of the bars. Green color illustrates the pathways that contain more than $50 \%$ of genes which found up-regulated in case (always the first group in each graph title) versus control (always the second group in graph title). While the pPathways containing more than $50 \%$ of genes up-regulated in control versus case, are illustrated with red color. $\mathrm{A}$. GS $\geqq \geq 8$ cancer vs. GS=6 cancer, $\mathrm{B}$. GS=6 cancer vs. GS=6 benign, C. GS $\geq>8$ cancer vs. $G S \geqq>8$ benign and $D$. all cancers $G S 6$ and $G S>8$ cancer vs. all $G S 6$ and $G S>8$ benigns.

To further evaluate our findings, the differentially expressed proteins from the comparison of cancer (GS=6 and $G S \geq 8$ ) versus benign ( $G S=6$ and $G S \geq 8$ ) were analysed on the Open Targets Platform [56] which combines evidence from various data sources, allowing target identification,-and prioritisation, as well as-and association with diseases. The analysis demonstrated that out of the 180 significantly differentially expressed proteins found in this comparison, 106 have been significantly (stat. test $p$-value $\leq-0.05$ ) associated with prostate cancer including prostate carcinoma and adenocarcinoma ${ }_{L}$ and metastatic prostate cancer. Furthermore, out of these 106 PCa associations, 86 were also associated with other urological cancers (bladder, kidney and testicular carcinoma) while 19 more proteins were found to be implicated only in other urological cancers and not in prostate malignancies. The results of the disease association analysis are shown in detail in Table S5. The high percentage of associations with PCa in this analysis supports the relevance of our proteomics results in the context of PCa and the efficiency of the optimized protein extraction protocol used for FFPE samples.

\section{Discussion}

There are relatively few published proteomic analyses of FFPE prostate tissues [6] (summarized in Table S6a). The majority of the studies focused on methodological approaches of extracting proteins from FFPE blocks using either low resolution proteomics techniques or applying LC-MS/MS with extensive fractionation and expensive labeling protocols [19-21,57-59]. SpecificallyCharacteristically, there are three proteomic reports using an SDS-based extraction protocol combined with heating and LC-MS/MS as proteomic platform to elucidate protein differences between FFPE PCa tissues and the adjacent counterparts. Using a case-control study design, Dunne et al. [23] used LC-MS/MS to identify protein changes between 16 primary PCa cases of GS 6-10 and 16 adjacent benign areas $\dot{\bar{\prime}}$ in this study, resulting in 242 protein IDs, in total. In a similar report, Iglesias et al.. using an SDS--based extraction buffer and LC-MS/MS with extensive fractionation of the samples, were able to identify 649 differentially expressed proteins between 28 PCa samples (GS 6-9) and 8 adjacent nonmalignant tissues [22]. Moreover, Turiak et al. used tissue microarrays TMAs from FFPE blocks, including 10 cases of PCa and 2 healthy prostate tissues, resulting in the identification of 500 proteins on average ${ }_{2}$ from each sample $_{L}$ using label-free quantitative LC-MS/MS analysis, also showing high grade of technical reproducibility 
[8]. A cumulative table of the proteomic studies using FFPE tissues in the context of PCa and their main characteristics is presented (Table S6a). A comparison of the differentially expressed proteins in the current study with the significantly altered proteins reported by Iglesias-Gato et al. [22] (PCa GS 6-9 vs adjacent benign) is presented in Table $\mathrm{S} 6 \mathrm{~b}$, as it is the only study performing a similar comparison to ours (PCa GS=6 and GS $\geq 8$ vS adjacent benign). In total, 107 proteins were differentially expressed in both studies, out of which, 83 follow the same expression trend in cancer compared to adjacent benign.

Our overall goal for this study was to investigate whether differential protein expression analysis from archival FFPE prostate cancer tissues with a simple, fast and label-free protocol using high resolution proteomics is feasible. Following an initial method development phase evaluating eightseven different protocols, compiling information from the existing literature [19-21,57-59], use of an extraction buffer including 100mM Tris- $\mathrm{HCl}, 4$ $\%$ SDS, 100mM DTE in combination with bead homogenization, sonication and boiling was selected.

This optimized buffer contained 4\% SDS, higher than the least-recommended concentration for such analyses (2\% SDS; [60]) and reported to effectively solubilize fixed proteins from FFPE tissues due to its dual denaturing and detergent actions [15,61].- Increase in protein extraction efficacy was noted when this buffer was combined with at least $60{ }^{\circ} \mathrm{C}$ heating. This is in line to several studies supporting a direct correlation between the protein yield from FFPE specimens and applied temperature $[18,59,62,63]$. Specifically, it has been suggested that heating may lead to protein unfolding, removal of covalent cross-links and hydrolysis of methylene bridges [62-64] with optimal results obtained at $65^{\circ} \mathrm{C}$ [59]. Besides the temperature, the effect of $\mathrm{pH}$ on the protein extraction efficacy has also been reported $[16,59,62]$. Several studies agree on the general finding that incubation of FFPE sections in buffers with basic $\mathrm{pH}(\sim 8.0)$ give higher yield ${ }_{2}$ while extraction in acidic or close to neutral pH ( 7-7.5), generally provide a lower protein amount $[16,59,62]$. Our protocol ${ }_{2}$ which includes an extraction buffer with $\mathrm{pH} \sim 2.0+$, is also in line with these reports.

$\underline{\text { Several studies aim Fargeting to evaluate if the FFPE tissues form offer a reliable alternative to fresh frozenFF }}$ samples, several studies have been performed by comparing the protein profiles between the two types of samples [59,60,65-67]. Overlaps in protein identifications between the FFPE and FF samples are in general high, with rates-ranging between 75 and 92\% [59,60,65-67]. Higher variability is noted in the number of identified proteins per study: In some cases, clear superiority of the FF over the FFPE samples [15,65,68,69]_was observed , while others reported comparable results $[70,71]$. In one case, a higher number of protein identifications (by about 30\%) in FFPE samples compared to FF tissue was observed reported [72]. These results may largely reflect differences among individual protocols but also the potential impact of the fixation protocols and storage conditions, which cannot generally not be controlled, generally, when analyzing archival tissues. In our analysis, the described protocol resulted in the detection of about 1000950 proteins on average, in FFPE samples, which 
361 is still lower to the respective FF output (about 1,500 proteins on average, per sample). However, the two types 362 of samples had with high overlap rates in their protein IDs (95\% of the FFPE and $41 \%$ of the FF protein IDs were 363 common) and significant correlation $\left(r_{s}=0.8460 .819, p<0.01\right)$ in the relative protein abundances, when the 364 FFPE tissues were compared with the respective FF tissues. Additionally, GO analysis supported-showed that similar percentages of membrane proteins isolated from FFPE and FF tissues were detected. This further suggests supports the efficacy of the applied protocol and its potential usefulness in the study of tumortumorrelevant signaling pathways.

In the context of this study, the optimized protocol was implemented in a proof of concept analysis of 18 FFPE PCa tissue samples, representing $G S=6, G S \geq 8$ and respective adjacent benign regions. Of the detected proteins, the vast number-majority of the high abundance identifications were cytoskeletal and ribosomal proteins, as well as nuclear histones, as expected [73]. Comparisons of the different groups highlighted many 372 expected protein changes in cancer, based on the current literature. These include as examples, Peroxiredoxins 3733 and 4-(PRDX3 and PRDX4), Methylcrotonoyl - CoA carboxylase beta chain-(ACCC2), Vinculin-(VCL) and 374 Prohibitin-(PHB), previously validated in more than one study as deregulated in PCa compared to adjacent 375 benign tissues ${ }_{L}$-similarly-found to-differentially expressed and-with same trends of expression in the studied 376 cancer cases versus adjacent controls [6]. Interestingly, in the comparisons GS $\geq 8$ versus GS=6 cancerous tissues, $377 \mathrm{GS} \geq 8$ adjacent benign tissues versus $\mathrm{GS}=6$ adjacent benign tissues, $\mathrm{GS} \geq 8$ cancerous tissues versus $\mathrm{GS} \geq 8$ adjacent 378 benign tissues, albeit non-statistically significant in the two latter cases, PSA was found down-regulated by at 379 least $0.2-$-fold, in GS $\geq 8$ groups, in the aforementioned comparisons. This finding is also supported by a targeted 380 proteomic study utilizing Selected Reaction Monitoring (SRM) in tissue samples where it was shown that PSA 381 levels decreased in localized PCa (GS=7) and in metastatic PCa tumors when compared to benign tissues [74]. 382 Multiple additional proteins (in total 25 out 63 [75]) earlier reported to differ in cancer versus benign [75] were 383 also detected as differentially expressed in our respective comparison ${ }_{\frac{5}{;}}$ Out of these 25 proteins, 21 exhibit the 384 same expression trend in our data and previous reports [75]; these include Keratin, type II cytoskeletal 8, 385 Peroxiredoxin-4, Growth/differentiation factor 15, Eukaryotic initiation factor 4A-III, Metalloproteinase inhibitor $3861_{2}$ that and others were specifically found also to agree in the expression trend in similar comparison groups as 387 in our study (Table S6S7).

388 The relevance of the proteomics output result ebserved at the individual protein level-was also observed 389 when investigating biological processes reflected by the observed protein changes, with Neutrophil 390 degranulation [76], Rho GTPase signaling [77]_mRNA metabolic processes_[54], glycolysis/glyconeogenesis 391 pathway [54]- and mitogen-activated protein kinases (MAPK)-signaling_[78]_predicted to be changing in GS $\geq 8$ vs $392 \mathrm{GS}=6$ as earlier reported. Similarly, significantly deregulated proteins in cancer versus benign segregated into 
pathways relevant to cancer molecular pathology such as or and protein translation [55], ECM organization [79] and mRNA splicing [80]. in cancer versus benign, as earlier reported. Collectively, these results support the reliability of the established procedure and further applicability to extract valuable information at the protein level, forming the basis for its further use in large scale PCa -related molecular studies.

Along the same lines, since androgen receptor (AR) signaling is known to play an important role in the 398 pathogenesis of PCa $[81,82]$, we also investigated the differentially expressed proteins in our comparisons in 399 regards to their association with the AR pathway (based on PathCards $[83,84]$ ). Interestingly, AR-linked proteins 400 were included, namely, Filamin-A (GS $\geq 8$ cancer vs. GS=6 cancer; GS=6 cancer vs. GS=6 benign); GTP-binding 401 nuclear protein Ran A (GS $\geq 8$ cancer vs. GS=6 cancer; GS=6 cancer vs. GS=6 benign); Destrin (GS $\geq 8$ cancer vs. $402 \mathrm{GS}=6$ cancer); Caveolin-1 (GS $\geq 8$ cancer vs. GS=6 cancer); Prostate-specific antigen (GS $\geq 8$ cancer vs. GS=6 cancer); 403 and Receptor of activated protein C kinase 1 (GS=6, GS $\geq 8$ cancer vs. GS=6, GS $\geq 8$ benign; GS=6 cancer vs. GS=6 404 benign). Additional proteins from our datasets, that are linked to the pathway but did not pass our criteria for 405 differential expression, include Catenin beta-1; Cell division control protein 42 homolog; Calreticulin; 406 Protein/nucleic acid deglycase DJ-1; and Peroxiredoxin-1. These findings further enhance the validity of our 407 proteomic results but the analysis of a bigger cohort is needed to draw solid conclusions with respect to the 408 biological relevance of these results.

$409 \quad$ It should be noted that the analyzed sections contain stroma elements and no specific enrichment for 410 epithelial components was made in the context of this pilot study. Upon comparison with an earlier proteomic 411 analysis of normal and diseased stroma isolated from PCa patients [85], an overlap of 30-40 proteins from the 412 earlier described differentially expressed proteins with the total protein identification from each of the 413 comparisons in our study may be seen, which might reflect the stroma influence in the results. described protocols, is simple and fast, applicable to limited amounts of clinical samples (as expected in the 418 cases of small pieces of tissue biopsies), yielding comprehensive datasets that permit further investigation and 419 knowledge extraction. With no doubt, due to the expected variability associated with differences in fixation and 420 storage conditions, future studies should include the analysis of large numbers of well characterized FFPE 421 samples with advanced LC/MS-MS approaches, targeting to reliably reveal protein changes associated with PCa 422 phenotypes and progression.

423

424 SUPPORTING INFORMATION: 
425 Figure S1. Protocol optimization for protein extraction from the FFPE blocks. Impact of buffer and

426 homogenization means on extracted proteins as defined by SDS-PAGE.

427 Figure S2. GO Molecular functional comparative analysis between FF and FFPE tissues. The genes corresponding 428 to the total number of proteins that totally-identified in FF and FFPE samples were mapped using the Gene 429 Ontology term mapper (https://go.princeton.edu/cgi-bin/GOTermMapper) for molecular functions. 430 ImportantlyAs shown, the genes are distributed between the molecular functions in a very similar way in the FFPE and the FF samples.

432 Table S1. Clinical characteristics of the patient cohort. This study comprised 10 patients with histologically 433 confirmed PCa in radical prostatectomy. Five patients had Gleason score $6(3+3)$ and five patients has Gleason 434 scores $8(4+4)$ and $9(4+5$ or $5+4)$. Here, specimens of the primary tumors that were investigated were-stored as 435 FFPE blocks were analyzed.

436 Table S2. Enrichment analysis for Reactome pathways for the comparisons (a) GS $\geq 8$ cancer vs. GS $\geq 8$ benign, (b) $437 \mathrm{GS}=6$ cancer vs. GS=6 benign, (c) Cancer ( $G S=6, G S \geq 8$ ) vs. Benign (GS=6, GS $\geq 8$ ), (d) $G S \geq 8$ cancer vs. GS=6 cancer, 438 (e) $G S \geq 8$ benign vs. $G S=6$ benign. Only the significantly differentially expressed proteins were used as input and 439 only the leading terms based on significance are presented. Enrichment analysis for Reactome pathways for the 440 comparisons GS $\geq 8$ cancer vs. GS $\geq 8$ benign (Table S2a), GS=6 cancer vs. GS=6 benign (Table S2b), Cancer $441(G S=6, G S \geq 8)$ vs. Benign ( $G S=6, G S \geq 8$ ) (Table $S 2 c), G S \geq 8$ cancer vs. GS=6 cancer (Table $S 2 d$ ), GS $\geq 8$ benign vs. GS=6 442 benign (Table S2e). Only the significantly differentially expressed proteins were input and only the leading terms 443 based on significance are presented.

$444 \quad$ Table S3. All proteins detected per sample as well as a Spearman's correlation analysis between FFPE and FF 445 mouse kidney tissues are shown (a) All proteins detected per sample are listed below. The raw area values are 446 given. Zeros indicate the missing values, the proteins that have not been detected (b) Correlation analysis between FFPE and FF mouse kidney tissues. The numbers given refer to proteins which were present in ALL the replicates per group. Spearman's correlation values have been calculated per wise for the samples individually but also for the average values.All proteins detected per sample as well as a Spearman's correlation analysis 450 between FFPE and FF mouse kidney tissues are shown.

451 Table S4. a) All proteins detected per sample in the clinical FFPE tissues are shown. Differential expression 452 analysis for the comparisons (b) GS $\geq 8$ cancer vs. GS=6 cancer, (c) GS $\geq 8$ benign vs. GS=6 benign, (d) GS=6 cancer 453 vs. $G S=6$ benign, (e) $G S \geq 8$ cancer vs. $G S \geq 8$ benign, (f) Cancer (GS=6, GS $\geq 8$ ) vs. Benign (GS=6, GS $\geq 8$ ) are given 454 indicating the proteins below the threshold for significance ( $p$-value $\leq 0.05$ ) and with an abundance ratio $\geq 1.5$ 455 with green color and proteins with $p$-value $\leq 0.05$ and abundance ratio $\leq 0.67$ with red color. (g) Summary of the 456 significantly deregulated proteins per comparison.All proteins detected per sample in the clinical FFPE tissues 
457 are shown. Differential expression analysis for all the comparison groups are given as well indicating the proteins 458 below the threshold for significance $(p-v a l \leq 0.05)$ and with an abundance ratio $\geq 1.5$ with green color and 459 proteins with $p-v a l \leq 0.05$ and abundance ratio $\leq 0.67$ with red color.

460 Table S5. Results from the disease association of the significantly differentially expressed proteins in the 461 comparison $G S \geq 8, G S=6$ of all cancers (case) $\underline{\forall} \forall s \in S \geq 8, G S=6$ all adjacent benign (control) using the Open Targets 462 Platform.

463 Table S6 (a) An overview of proteomics studies performed in FFPE tissues in the context of prostate cancer. (b) 464 Comparison of the findings in the current study with the study by Iglesias-Gato et al. 2015 (PMID: 26651926) in 465 the same comparison between Tumor $(n=28)$ and adjacent non-malignant prostate tissue ( $n=8)$. Multiple 466 proteins (in total 107 out of 649), earlier reported to differ in cancer versus benign, were also detected as 467 differentially expressed in our respective comparison GS $\geq 8, G S=6$ cancer (case) vs adjacent benign GS $\geq 8, G S=6$ 468 (control). Proteins that exhibit the same expression trend are highlighted.

469 Table S76. Comparison of the findings in the current study with the literature (review, PMID: 29939814). 470 Multiple proteins (in total 25 out of 63), earlier reported to differ in cancer versus benign, were also detected 471 as differentially expressed in our respective comparison $G S \geq 8, G S=6$ cancer (case) vs adjacent benign $G S \geq 8, G S=6$ 472 (control). Proteins that exhibit the same expression trend in similar comparisons in our data and previous 473 reports are highlighted. Comparison of the findings in the current study with the literature (Review 2017). 474 Multiple proteins (in total 25 out 63) earlier reported to differ in cancer versus benign were also detected as 475 differentially expressed in our respective comparison GS8, GS6 cancer(case) Vs adjacent benignGS $\geq 8$, GS=6 476 (control); Proteins that exhibit the same expression trend and in similar comparison groups in our data and 477 previous reports are highlighted.

\section{$479 \quad$ Funding}

480 This work was supported by Translational Research Network for Prostate Cancer (721746 - TransPot - H2020 $481 \quad$ MSCA - ITN - 2016) 721746.

482

\section{Conflict of interest}

484 All authors declare no competing financial interest.

485

\section{References}


488 [1] Bray F, Ferlay J, Soerjomataram I, Siegel RL, Torre LA, Jemal A. Global cancer statistics 2018: GLOBOCAN

489

490

491

492

493

494

495

496

497

498

499

500

501

502

503

504

505

506

507

508

509

510

511

512

513

514

515

516

517

518

519

520

521

522 estimates of incidence and mortality worldwide for 36 cancers in 185 countries. CA Cancer J Clin 2018;68:394-424. doi:10.3322/caac.21492.

[2] Romero Otero J, Garcia Gomez B, Campos Juanatey F, Touijer KA. Prostate cancer biomarkers: an update. Urol Oncol 2014;32:252-260. doi:10.1016/j.urolonc.2013.09.017.

[3] Prensner JR, Rubin MA, Wei JT, Chinnaiyan AM. Beyond PSA: the next generation of prostate cancer biomarkers. Sci Transl Med 2012;4:127rv3. doi:10.1126/scitransImed.3003180.

[4] Alford AV, Brito JM, Yadav KK, Yadav SS, Tewari AK, Renzulli J. The use of biomarkers in prostate cancer screening and treatment. Rev Urol 2017;19:221-234. doi:10.3909/riu0772.

[5] Frank S, Nelson P, Vasioukhin V. Recent advances in prostate cancer research: large-scale genomic analyses reveal novel driver mutations and DNA repair defects. [version 1; peer review: 2 approved]. F1000Res 2018;7. doi:10.12688/f1000research.14499.1.

[6] Mantsiou A, Vlahou A, Zoidakis J. Tissue proteomics studies in the investigation of prostate cancer. Expert Rev Proteomics 2018;15:593-611. doi:10.1080/14789450.2018.1491796.

[7] Müller A-K, Föll M, Heckelmann B, Kiefer S, Werner M, Schilling O, et al. Proteomic characterization of prostate cancer to distinguish nonmetastasizing and metastasizing primary tumors and lymph node metastases. Neoplasia 2018;20:140-151. doi:10.1016/j.neo.2017.10.009.

[8] Turiák L, Ozohanics O, Tóth G, Ács A, Révész Á, Vékey K, et al. High sensitivity proteomics of prostate cancer tissue microarrays to discriminate between healthy and cancerous tissue. J Proteomics 2019;197:82-91. doi:10.1016/j.jprot.2018.11.009.

[9] Sinha A, Huang V, Livingstone J, Wang J, Fox NS, Kurganovs N, et al. The proteogenomic landscape of curable prostate cancer. Cancer Cell 2019;35:414-427.e6. doi:10.1016/j.ccell.2019.02.005.

[10] Latonen L, Afyounian E, Jylhä A, Nättinen J, Aapola U, Annala M, et al. Integrative proteomics in prostate cancer uncovers robustness against genomic and transcriptomic aberrations during disease progression. Nat Commun 2018;9:1176. doi:10.1038/s41467-018-03573-6.

[11] Nirmalan NJ, Harnden P, Selby PJ, Banks RE. Mining the archival formalin-fixed paraffin-embedded tissue proteome: opportunities and challenges. Mol Biosyst 2008;4:712-720. doi:10.1039/b800098k.

[12] Knezevic D, Goddard AD, Natraj N, Cherbavaz DB, Clark-Langone KM, Snable J, et al. Analytical validation of the Oncotype DX prostate cancer assay - a clinical RT-PCR assay optimized for prostate needle biopsies. BMC Genomics 2013;14:690. doi:10.1186/1471-2164-14-690.

[13] Mason JT, O'Leary TJ. Effects of formaldehyde fixation on protein secondary structure: a calorimetric and infrared spectroscopic investigation. J Histochem Cytochem 1991;39:225-229. doi:10.1177/39.2.1987266.

[14] Matsuda KM, Chung J-Y, Hewitt SM. Histo-proteomic profiling of formalin-fixed, paraffin-embedded tissue. Expert Rev Proteomics 2010;7:227-237. doi:10.1586/epr.09.106. 
[15] Jiang X, Jiang X, Feng S, Tian R, Ye M, Zou H. Development of efficient protein extraction methods for shotgun proteome analysis of formalin-fixed tissues. J Proteome Res 2007;6:1038-1047. doi:10.1021/pr0605318.

[16] Azimzadeh O, Barjaktarovic Z, Aubele M, Calzada-Wack J, Sarioglu H, Atkinson MJ, et al. Formalin-fixed paraffin-embedded (FFPE) proteome analysis using gel-free and gel-based proteomics. J Proteome Res 2010;9:4710-4720. doi:10.1021/pr1004168.

[17] Magdeldin S, Yamamoto T. Toward deciphering proteomes of formalin-fixed paraffin-embedded (FFPE) tissues. Proteomics 2012;12:1045-1058. doi:10.1002/pmic.201100550.

[18] Ikeda K, Monden T, Kanoh T, Tsujie M, Izawa H, Haba A, et al. Extraction and Analysis of Diagnostically Useful Proteins from Formalin-fixed, Paraffin-embedded Tissue Sections. Journal of Histochemistry \& Cytochemistry 1998;46:397-403. doi:10.1177/002215549804600314.

[19] Hood BL, Darfler MM, Guiel TG, Furusato B, Lucas DA, Ringeisen BR, et al. Proteomic analysis of formalin-fixed prostate cancer tissue. Mol Cell Proteomics 2005;4:1741-1753. doi:10.1074/mcp.M500102-MCP200.

[20] Pallua JD, Schaefer G, Seifarth C, Becker M, Meding S, Rauser S, et al. MALDI-MS tissue imaging identification of biliverdin reductase B overexpression in prostate cancer. J Proteomics 2013;91:500514. doi:10.1016/j.jprot.2013.08.003.

[21] Davalieva K, Kiprijanovska S, Polenakovic M. Assessment of the 2-d gel-based proteomics application of clinically archived formalin-fixed paraffin embedded tissues. Protein J 2014;33:135-142. doi:10.1007/s10930-014-9545-2.

[22] Iglesias-Gato D, Wikström P, Tyanova S, Lavallee C, Thysell E, Carlsson J, et al. The proteome of primary prostate cancer. Eur Urol 2016;69:942-952. doi:10.1016/j.eururo.2015.10.053.

[23] Dunne JC, Lamb DS, Delahunt B, Murray J, Bethwaite P, Ferguson P, et al. Proteins from formalin-fixed paraffin-embedded prostate cancer sections that predict the risk of metastatic disease. Clin Proteomics 2015;12:24. doi:10.1186/s12014-015-9096-3.

[24] Makridakis M, Vlahou A. GeLC-MS: A Sample Preparation Method for Proteomics Analysis of Minimal Amount of Tissue. Methods Mol Biol 2018;1788:165-175. doi:10.1007/7651_2017_76.

[25] Mokou M, Klein J, Makridakis M, Bitsika V, Bascands J-L, Saulnier-Blache JS, et al. Proteomics based identification of KDM5 histone demethylases associated with cardiovascular disease. EBioMedicine 2019;41:91-104. doi:10.1016/j.ebiom.2019.02.040.

[26] Schanstra JP, Luong TTD, Makridakis M, Van Linthout S, Lygirou V, Latosinska A, et al. Systems biology identifies cytosolic PLA2 as a target in vascular calcification treatment. JCI Insight 2019.

[27] Korshak OV, Sushilova EN, Voskresenskii MA, Grozov RV, Komyakov BK, Zarytskey AY, et al. [Basalluminal epithelial cell differentiation in prostate cancer is associated with epithelial-mesenchymal transition and epithelium migration in the mesenchyme]. Urologiia 2016:85-91. 
558 [28] Amaro A, Esposito Al, Gallina A, Nees M, Angelini G, Albini A, et al. Validation of proposed prostate cancer biomarkers with gene expression data: a long road to travel. Cancer Metastasis Rev 2014;33:657-671. doi:10.1007/s10555-013-9470-4.

[29] Altintas DM, Allioli N, Decaussin M, de Bernard S, Ruffion A, Samarut J, et al. Differentially expressed androgen-regulated genes in androgen-sensitive tissues reveal potential biomarkers of early prostate cancer. PLoS One 2013;8:e66278. doi:10.1371/journal.pone.0066278.

[30] Valcarcel-Jimenez L, Macchia A, Martín-Martín N, Cortazar AR, Schaub-Clerigué A, Pujana-Vaquerizo M, et al. Integrative analysis of transcriptomics and clinical data uncovers the tumor-suppressive activity of MITF in prostate cancer. Cell Death Dis 2018;9:1041. doi:10.1038/s41419-018-1096-6.

[31] Burch TC, Watson MT, Nyalwidhe JO. Variable metastatic potentials correlate with differential plectin and vimentin expression in syngeneic androgen independent prostate cancer cells. PLoS One 2013;8:e65005. doi:10.1371/journal.pone.0065005.

[32] Hong SK, Ko DW, Park J, Kim IS, Doo SH, Yoon CY, et al. Alteration of Antithrombin III and D-dimer Levels in Clinically Localized Prostate Cancer. Korean J Urol 2010;51:25-29. doi:10.4111/kju.2010.51.1.25.

[33] Wang $Y$, Guo W, Xu H, Zhu X, Yu T, Jiang Z, et al. An extensive study of the mechanism of prostate cancer metastasis. Neoplasma 2018;65:253-261. doi:10.4149/neo_2018_161217N648.

[34] Elix C, Pal SK, Jones JO. The role of peroxisome proliferator-activated receptor gamma in prostate cancer. Asian J Androl 2018;20:238-243. doi:10.4103/aja.aja_15_17.

[35] Chng KR, Chang CW, Tan SK, Yang C, Hong SZ, Sng NYW, et al. A transcriptional repressor co-regulatory network governing androgen response in prostate cancers. EMBO J 2012;31:2810-2823. doi:10.1038/emboj.2012.112.

[36] Geisler C, Gaisa NT, Pfister D, Fuessel S, Kristiansen G, Braunschweig T, et al. Identification and validation of potential new biomarkers for prostate cancer diagnosis and prognosis using 2D-DIGE and MS. Biomed Res Int 2015;2015:454256. doi:10.1155/2015/454256.

[37] Suhovskih AV, Mostovich LA, Kunin IS, Boboev MM, Nepomnyashchikh GI, Aidagulova SV, et al. Proteoglycan expression in normal human prostate tissue and prostate cancer. ISRN Oncol 2013;2013:680136. doi:10.1155/2013/680136.

[38] Tyutyunnykova A, Telegeev G, Dubrovska A. The controversial role of phospholipase C epsilon (PLCE) in cancer development and progression. J Cancer 2017;8:716-729. doi:10.7150/jca.17779.

[39] Shapiro E, Huang H, Ruoff R, Lee P, Tanese N, Logan SK. The heterochromatin protein 1 family is regulated in prostate development and cancer. J Urol 2008;179:2435-2439. doi:10.1016/j.juro.2008.01.091.

[40] Basu A, Banerjee H, Rojas H, Martinez SR, Roy S, Jia Z, et al. Differential expression of peroxiredoxins in prostate cancer: consistent upregulation of PRDX3 and PRDX4. Prostate 2011;71:755-765. doi:10.1002/pros.21292. 
[41] Tiedemann K, Sadvakassova G, Mikolajewicz N, Juhas M, Sabirova Z, Tabariès S, et al. Exosomal Release of L-Plastin by Breast Cancer Cells Facilitates Metastatic Bone Osteolysis. Transl Oncol 2019;12:462-474. doi:10.1016/j.tranon.2018.11.014.

[42] Rose A, Xu Y, Chen Z, Fan Z, Stamey TA, McNeal JE, et al. Comparative gene and protein expression in primary cultures of epithelial cells from benign prostatic hyperplasia and prostate cancer. Cancer Lett 2005;227:213-222. doi:10.1016/j.canlet.2005.01.037.

[43] van Leenders GJ, Aalders TW, Hulsbergen-van de Kaa CA, Ruiter DJ, Schalken JA. Expression of basal cell keratins in human prostate cancer metastases and cell lines. J Pathol 2001;195:563-570. doi:10.1002/path.993.

[44] Shih JC. Monoamine oxidase isoenzymes: genes, functions and targets for behavior and cancer therapy. J Neural Transm 2018;125:1553-1566. doi:10.1007/s00702-018-1927-8.

[45] Feichtinger RG, Schäfer G, Seifarth C, Mayr JA, Kofler B, Klocker H. Reduced Levels of ATP Synthase Subunit ATP5F1A Correlate with Earlier-Onset Prostate Cancer. Oxid Med Cell Longev 2018;2018:1347174. doi:10.1155/2018/1347174.

[46] Orr B, Riddick ACP, Stewart GD, Anderson RA, Franco OE, Hayward SW, et al. Identification of stromally expressed molecules in the prostate by tag-profiling of cancer-associated fibroblasts, normal fibroblasts and fetal prostate. Oncogene 2012;31:1130-1142. doi:10.1038/onc.2011.312.

[47] Zhang X, Hu L, Du M, Wei X, Zhang J, Hui Y, et al. Eukaryotic elongation factor 2 (eef2) is a potential biomarker of prostate cancer. Pathol Oncol Res 2018;24:885-890. doi:10.1007/s12253-017-0302-7.

[48] Planchon SM, Pink JJ, Tagliarino C, Bornmann WG, Varnes ME, Boothman DA. beta-Lapachone-induced apoptosis in human prostate cancer cells: involvement of NQO1/xip3. Exp Cell Res 2001;267:95-106. doi:10.1006/excr.2001.5234.

[49] Kumi-Diaka J, Saddler-Shawnette S, Aller A, Brown J. Potential mechanism of phytochemical-induced apoptosis in human prostate adenocarcinoma cells: Therapeutic synergy in genistein and betalapachone combination treatment. Cancer Cell Int 2004;4:5. doi:10.1186/1475-2867-4-5.

[50] Heger Z, Michalek P, Guran R, Cernei N, Duskova K, Vesely S, et al. Differences in urinary proteins related to surgical' ' margin status after radical prostatectomy. Oncol Rep 2015;34:3247-3255. doi:10.3892/or.2015.4322.

[51] Feng J, Huang C, Diao X, Fan M, Wang P, Xiao Y, et al. Screening biomarkers of prostate cancer by integrating microRNA and mRNA microarrays. Genet Test Mol Biomarkers 2013;17:807-813. doi:10.1089/gtmb.2013.0226.

[52] Miller D, Ingersoll M, Lin M-F. ErbB-2 signaling in advanced prostate cancer progression and potential therapy. Endocr Relat Cancer 2019;26:R195-R209. doi:10.1530/ERC-19-0009.

[53] Srihari S, Kwong R, Tran K, Simpson R, Tattam P, Smith E. Metabolic deregulation in prostate cancer. Mol Omics 2018;14:320-329. doi:10.1039/c8mo00170g. 
628 [54] Kelly RS, Sinnott JA, Rider JR, Ebot EM, Gerke T, Bowden M, et al. The role of tumor metabolism as a

629

630

631

632

633

634

635

636

637

638

639

640

641

642

643

644

645

646

647

648

649

650

651

652

653

654

655

656

657

658

659

660

661

662

663

664 driver of prostate cancer progression and lethal disease: results from a nested case-control study. Cancer Metab 2016;4:22. doi:10.1186/s40170-016-0161-9.

[55] Ramamurthy VP, Ramalingam S, Kwegyir-Afful AK, Hussain A, Njar VCO. Targeting of protein translation as a new treatment paradigm for prostate cancer. Curr Opin Oncol 2017. doi:10.1097/CCO.0000000000000367.

[56] Carvalho-Silva D, Pierleoni A, Pignatelli M, Ong C, Fumis L, Karamanis N, et al. Open Targets Platform: new developments and updates two years on. Nucleic Acids Res 2019;47:D1056-D1065. doi:10.1093/nar/gky1133.

[57] Chu W-S, Liang Q, Liu J, Wei MQ, Winters M, Liotta L, et al. A nondestructive molecule extraction method allowing morphological and molecular analyses using a single tissue section. Lab Invest 2005;85:1416-1428. doi:10.1038/labinvest.3700337.

[58] Hwang SI, Thumar J, Lundgren DH, Rezaul K, Mayya V, Wu L, et al. Direct cancer tissue proteomics: a method to identify candidate cancer biomarkers from formalin-fixed paraffin-embedded archival tissues. Oncogene 2007;26:65-76. doi:10.1038/sj.onc.1209755.

[59] Chung J-Y, Lee S-J, Kris Y, Braunschweig T, Traicoff JL, Hewitt SM. A well-based reverse-phase protein array applicable to extracts from formalin-fixed paraffin-embedded tissue. Proteomics Clin Appl 2008;2:1539-1547. doi:10.1002/prca.200800005.

[60] Shi S-R, Liu C, Balgley BM, Lee C, Taylor CR. Protein extraction from formalin-fixed, paraffin-embedded tissue sections: quality evaluation by mass spectrometry. J Histochem Cytochem 2006;54:739-743. doi:10.1369/jhc.5B6851.2006.

[61] Ha GH, Lee SU, Kang DG, Ha N-Y, Kim SH, Kim J, et al. Proteome analysis of human stomach tissue: separation of soluble proteins by two-dimensional polyacrylamide gel electrophoresis and identification by mass spectrometry. Electrophoresis 2002;23:2513-2524. doi:10.1002/15222683(200208)23:15<2513::AID-ELPS2513>3.0.CO;2-W.

[62] Yamashita S. Heat-induced antigen retrieval: mechanisms and application to histochemistry. Prog Histochem Cytochem 2007;41:141-200. doi:10.1016/j.proghi.2006.09.001.

[63] Rait VK, Xu L, O'Leary TJ, Mason JT. Modeling formalin fixation and antigen retrieval with bovine pancreatic RNase A II. Interrelationship of cross-linking, immunoreactivity, and heat treatment. Lab Invest 2004;84:300-306. doi:10.1038/labinvest.3700041.

[64] Addis MF, Tanca A, Pagnozzi D, Crobu S, Fanciulli G, Cossu-Rocca P, et al. Generation of high-quality protein extracts from formalin-fixed, paraffin-embedded tissues. Proteomics 2009;9:3815-3823. doi:10.1002/pmic.200800971.

[65] Sprung RW, Brock JWC, Tanksley JP, Li M, Washington MK, Slebos RJC, et al. Equivalence of protein inventories obtained from formalin-fixed paraffin-embedded and frozen tissue in multidimensional liquid chromatography-tandem mass spectrometry shotgun proteomic analysis. Mol Cell Proteomics 2009;8:1988-1998. doi:10.1074/mcp.M800518-MCP200. 
[66] Scicchitano MS, Dalmas DA, Boyce RW, Thomas HC, Frazier KS. Protein extraction of formalin-fixed, paraffin-embedded tissue enables robust proteomic profiles by mass spectrometry. J Histochem Cytochem 2009;57:849-860. doi:10.1369/jhc.2009.953497.

[67] Guo T, Wang W, Rudnick PA, Song T, Li J, Zhuang Z, et al. Proteome analysis of microdissected formalinfixed and paraffin-embedded tissue specimens. J Histochem Cytochem 2007;55:763-772. doi:10.1369/jhc.7A7177.2007.

[68] Nirmalan NJ, Harnden P, Selby PJ, Banks RE. Development and validation of a novel protein extraction methodology for quantitation of protein expression in formalin-fixed paraffin-embedded tissues using western blotting. J Pathol 2009;217:497-506. doi:10.1002/path.2504.

[69] Gräntzdörffer I, Yumlu S, Gioeva Z, von Wasielewski R, Ebert MPA, Röcken C. Comparison of different tissue sampling methods for protein extraction from formalin-fixed and paraffin-embedded tissue specimens. Exp Mol Pathol 2010;88:190-196. doi:10.1016/j.yexmp.2009.09.009.

[70] Hood BL, Conrads TP, Veenstra TD. Mass spectrometric analysis of formalin-fixed paraffin-embedded tissue: unlocking the proteome within. Proteomics 2006;6:4106-4114. doi:10.1002/pmic.200600016.

[71] Becker KF, Schott C, Hipp S, Metzger V, Porschewski P, Beck R, et al. Quantitative protein analysis from formalin-fixed tissues: implications for translational clinical research and nanoscale molecular diagnosis. J Pathol 2007;211:370-378. doi:10.1002/path.2107.

[72] Palmer-Toy DE, Krastins B, Sarracino DA, Nadol JB, Merchant SN. Efficient method for the proteomic analysis of fixed and embedded tissues. J Proteome Res 2005;4:2404-2411. doi:10.1021/pr050208p.

[73] Wang D, Eraslan B, Wieland T, Hallström B, Hopf T, Zolg DP, et al. A deep proteome and transcriptome abundance atlas of 29 healthy human tissues. Mol Syst Biol 2019;15:e8503. doi:10.15252/msb.20188503.

[74] Yocum AK, Khan AP, Zhao R, Chinnaiyan AM. Development of selected reaction monitoring-MS methodology to measure peptide biomarkers in prostate cancer. Proteomics 2010;10:3506-3514. doi:10.1002/pmic.201000023.

[75] Tanase CP, Codrici E, Popescu ID, Mihai S, Enciu A-M, Necula LG, et al. Prostate cancer proteomics: Current trends and future perspectives for biomarker discovery. Oncotarget 2017;8:18497-18512. doi:10.18632/oncotarget.14501.

[76] Kolonin M, Sergeeva A, Staquicini D, Molldrem JJ, Pasqualini R, Arap W. Neutrophil-Secreted Proteinase 3 Mediates Metastasis of Prostate Cancer Cells Expressing RAGE to the Bone Marrow. Blood 2016;128:1025-1025. doi:10.1182/blood.V128.22.1025.1025.

[77] Engers R, Ziegler S, Mueller M, Walter A, Willers R, Gabbert HE. Prognostic relevance of increased Rac GTPase expression in prostate carcinomas. Endocr Relat Cancer 2007;14:245-256. doi:10.1677/ERC-060036.

[78] Rodríguez-Berriguete G, Fraile B, Martínez-Onsurbe P, Olmedilla G, Paniagua R, Royuela M. MAP Kinases and Prostate Cancer. J Signal Transduct 2012;2012:169170. doi:10.1155/2012/169170. 
701 [79] Walker C, Mojares E, Del Río Hernández A. Role of extracellular matrix in development and cancer 702 progression. Int J Mol Sci 2018;19. doi:10.3390/ijms19103028.

703 [80] Antonopoulou E, Ladomery M. Targeting splicing in prostate cancer. Int J Mol Sci 2018;19.

704 doi:10.3390/ijms19051287.

705

[81] Culig Z, Santer FR. Androgen receptor signaling in prostate cancer. Cancer Metastasis Rev 2014;33:413427. doi:10.1007/s10555-013-9474-0.

707 [82] Dai C, Heemers H, Sharifi N. Androgen signaling in prostate cancer. Cold Spring Harb Perspect Med 708

709

710

711

712

713

714 2017;7. doi:10.1101/cshperspect.a030452.

[83] Belinky F, Nativ N, Stelzer G, Zimmerman S, Iny Stein T, Safran M, et al. PathCards: multi-source consolidation of human biological pathways. Database (Oxford) 2015;2015. doi:10.1093/database/bav006.

[84] Androgen receptor signaling pathway. PathCards Pathway Unification Database n.d. https://pathcards.genecards.org/Card/androgen_receptor_signaling_pathway?queryString=ANDROGEN (accessed October 14, 2019).

[85] Webber JP, Spary LK, Mason MD, Tabi Z, Brewis IA, Clayton A. Prostate stromal cell proteomics analysis discriminates normal from tumour reactive stromal phenotypes. Oncotarget 2016;7:20124-20139. doi:10.18632/oncotarget.7716. 


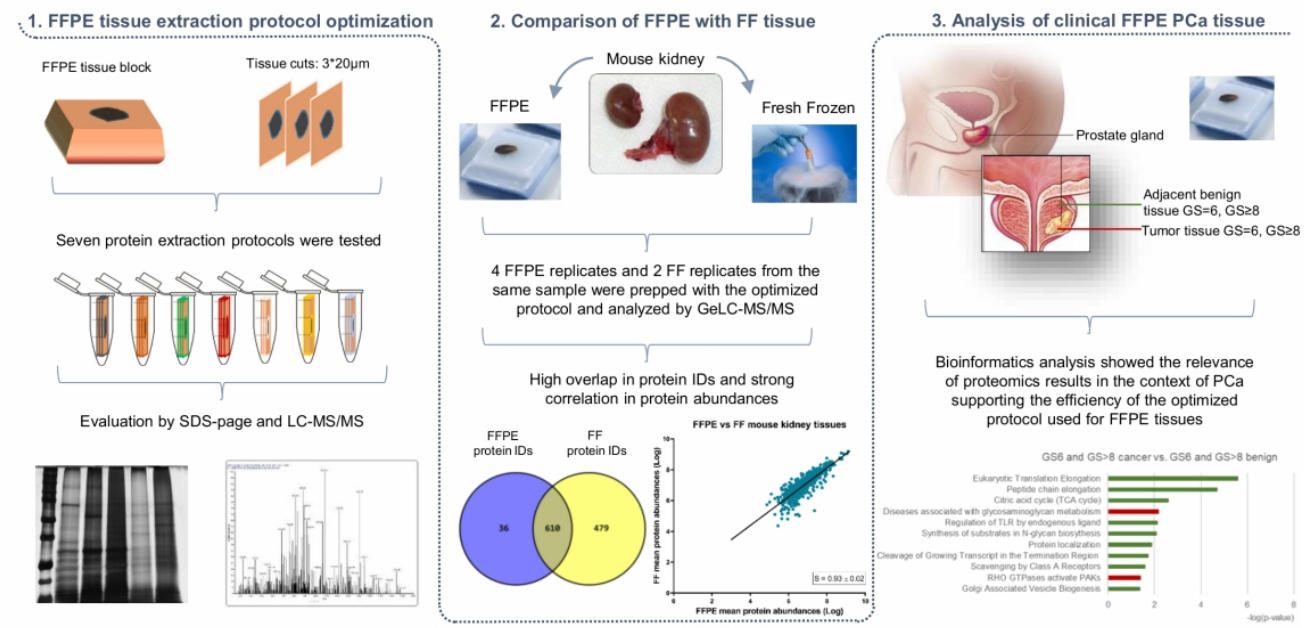

$203 \times 101 \mathrm{~mm}(300 \times 300$ DPI $)$ 